\title{
Role of the long non-coding RNA HOTAIR/miR-126 axis in an in vitro psoriasis model
}

\author{
WEIFENG ZHA ${ }^{1}$, BO GUO ${ }^{2}$, SHUYUE CHEN ${ }^{1}$, JUNWEI LU $^{3}$ and YUNYUN SHAN ${ }^{1}$ \\ ${ }^{1}$ Department of Dermatology, Third People's Hospital of Hangzhou, Hangzhou, Zhejiang 310009; \\ ${ }^{2}$ Department of Dermatology, Tongxiang Dermatosis Prevention Institute, Tongxiang, \\ Zhejiang 314500; ${ }^{3}$ Department of Acupuncture, Integrated Chinese and Western \\ Medicine Hospital of Xihu, Hangzhou, Zhejiang 310030, P.R. China
}

Received June 15, 2020; Accepted October 6, 2020

DOI: $10.3892 /$ etm.2021.9878

\begin{abstract}
Psoriasis is a T-cell-mediated inflammatory skin disease that is characterized by excessive keratinocyte proliferation and persistent skin inflammation. Accumulating evidence suggests that long non-coding RNAs (lncRNAs) are dysregulated in a number of inflammatory conditions. In the present study, an in vitro psoriasis cell model was established. Human HaCaT keratinocytes were activated using the inflammatory factor IL-22. Briefly, HaCaT cells were starved in serum-free DMEM for $24 \mathrm{~h}$ and then stimulated with $100 \mathrm{ng} / \mathrm{ml}$ IL-22 in serum-free DMEM for $24 \mathrm{~h}$. Previous research indicated that HOX transcript antisense RNA (HOTAIR) may participate in the development of psoriasis. First, reverse transcription-quantitative PCR (RT-qPCR) analysis was performed to detect HOTAIR expression. The results indicated that HOTAIR expression was reduced in IL-22-stimulated $\mathrm{HaCaT}$ cells. Subsequently, a dual-luciferase reporter assay was performed to verify the binding site between HOTAIR and microRNA (miR)-126. The RT-qPCR results indicated that miR-126 expression was increased in IL-22-stimulated $\mathrm{HaCaT}$ cells. Moreover, the effects of HOTAIR and miR-126 on IL-22-stimulated $\mathrm{HaCaT}$ cell proliferation and apoptosis were assessed. HaCaT cells were transfected with control-plasmid, HOTAIR-plasmid, HOTAIR-plasmid + mimic control or HOTAIR-plasmid + miR-126 mimic for $24 \mathrm{~h}$. At $24 \mathrm{~h}$ post-transfection, the cells were stimulated with $100 \mathrm{ng} / \mathrm{ml}$ IL-22 for $24 \mathrm{~h}$ and experiments were conducted. IL-22 induced cell proliferation and suppressed apoptosis. However, HOTAIR-plasmid inhibited cell viability and induced apoptosis in IL-22-stimulated HaCaT cells. In addition, the western blotting results indicated that HOTAIR-plasmid increased cleaved
\end{abstract}

Correspondence to: Dr Weifeng Zha, Department of Dermatology, Third People's Hospital of Hangzhou, 38 Xihu Avenue, Hangzhou, Zhejiang 310009, P.R. China

E-mail:w787768@163.com

Key words: long non-coding RNA-HOX transcript antisense RNA, microRNA-126, psoriasis, interleukin-22-induced $\mathrm{HaCaT}$ cells caspase-3 expression and the cleaved caspase-3/caspase-3 ratio, whereas the HOTAIR-plasmid-mediated effects were reversed by miR-126 mimic. Collectively, the results of the present study demonstrated that the lncRNA-HOTAIR/miR-126 axis may be implicated in the regulation of psoriasis progression and may serve as a potential therapeutic target for psoriasis.

\section{Introduction}

Psoriasis is a relatively common chronic inflammatory skin disease that adversely affects the lives of the patients (1). Psoriasis affects $2-3 \%$ of the population worldwide $(2,3)$. Previous research indicates that psoriasis is associated with a number of complications, including psoriatic arthritis, cardiovascular diseases, Crohn's disease, anxiety and depression, with the occurrence of these diseases increasing the mortality risk $(4,5)$. It has been reported that certain therapeutic strategies may be used to treat psoriasis with good results, including local therapy, physical therapy, systemic therapy and new biological agents (such as TNF- $\alpha$, IL-12/23 and IL-17 inhibitors), but the recurrence rate of psoriasis remains high (6-8). Therefore, identifying a novel therapeutic strategy for psoriasis would be beneficial. It was previously demonstrated that IL-22 regulates human keratinocyte proliferation and increases IL-22 expression in the serum and skin lesions of patients with psoriasis (9). Therefore, IL-22 may play a key role in the development of psoriasis (10). In addition, IL-22-induced skin inflammation was reported in a mouse model, further suggesting that IL-22 is associated with psoriasis (10).

Integrated genomic and transcriptome sequencing results have demonstrated that $>90 \%$ of DNA sequences are actively transcribed, $98 \%$ of which are transcribed into non-coding RNA (ncRNA), including microRNAs (miRNAs/miRs) and long ncRNAs (lncRNAs) $(11,12)$. IncRNAs are transcripts that are $>200$ nucleotides in length with limited potential for protein coding (13). lncRNAs regulate gene expression at different levels and participate in a variety of biological processes $(14,15)$. Previous research has indicated that lncRNA may be abnormally expressed in mammalian and plant cells $(16,17)$. An increasing number of studies have demonstrated that lncRNAs may be used as biomarkers for diagnosing and predicting different types of cancer (18-23). 
Additional studies have reported that the abnormal expression of IncRNAs is closely associated with the occurrence and development of psoriasis $(24,25)$. Jia et al (26) demonstrated that the lncRNA MEG3 affects the proliferation and apoptosis of psoriatic epidermal cells via targeting miR-21/caspase-8. Gao et al (27) reported that the lncRNA MIR31HG may be a potential diagnostic biomarker and therapeutic target for psoriasis. Qiao et al (28) reported that the lncRNA msh homeobox 2 pseudogene 1 may participate in the occurrence of psoriasis. Previous research also indicated that the stress-induced lncRNA psoriasis-susceptibility-related RNA gene may play a key role in psoriasis (29). Tang et al (30) demonstrated that the lncRNA homeobox transcript antisense RNA (HOTAIR) acts as an oncogene in human cancer. Moreover, Yang et al (31) indicated that HOTAIR enhanced liver cancer cell proliferation via promotion of epithelial-to-mesenchymal transition. A recent study indicated the presence of an association between a genomic variant within HOTAIR and the risk of psoriasis (32). However, the specific role and related mechanisms of HOTAIR in psoriasis remain to be further elucidated.

Numerous studies have reported that the expression of multiple miRNAs, such as miR-125b, miR-155 and miR-26b, is associated with the progression of psoriasis (33-35). It has also been demonstrated that miR-126 is highly expressed in the tissues of patients with psoriasis, but with lower plasma expression levels. Furthermore, miR-126 expression in the plasma of patients was found to be inversely correlated with the risk and severity of psoriasis. In addition, a mutual binding site between IncRNA HOTAIR and miR-126 has been identified $(36,37)$. Therefore, it may be hypothesized that the lncRNA HOTAIR is involved in the occurrence and development of psoriasis through regulation of miR-126 expression.

The aim of the present study was to explore whether HOTAIR was involved in psoriasis through modulation of miR-126 expression, so as to provide more strategies and a theoretical basis for the treatment of psoriasis.

\section{Materials and methods}

Cell culture and transfection. Human HaCaT keratinocytes (CLS Cell Lines Service GmbH) were cultured in DMEM (Hyclone; Cytiva) supplemented with 10\% FBS (Gibco; Thermo Fisher Scientific, Inc.), $100 \mathrm{U} / \mathrm{ml}$ penicillin and $100 \mu \mathrm{g} / \mathrm{ml}$ streptomycin (Beyotime Institute of Biotechnology) at $37^{\circ} \mathrm{C}$ in a $5 \% \mathrm{CO}_{2}$ incubator. For overexpression of HOTAIR, full-length HOTAIR was amplified by PCR (primers: 5'-GACTCGCCTGTGCTCTGGAGCT-3' and 5'-TTGAA AATGCATCCAGATTTTT-3') and then cloned into the multiple cloning site of the pcDNA3.1 vector (Invitrogen; Thermo FisherScientific,Inc.) to construct the HOTAIR-plasmid. The empty pcDNA3.1 vector (Invitrogen; Thermo Fisher Scientific, Inc.) was used as the control-plasmid. Subsequently, HaCaT cells $\left(5 \times 10^{4}\right.$ cells per well; 6 -well plate) were transfected with $100 \mathrm{ng}$ control-plasmid, $100 \mathrm{ng}$ HOTAIR-plasmid, $100 \mathrm{nM}$ mimic control (sense: 5'-UUCUCCGAACGUGU CACGUTT-3'; anti-sense: 5'-ACGUGACACGUUCGGAGA ATT-3'; GenePharma), 100 nM miR-126 mimic (sense: 5'-UCG UACCGUGAGUAAUAAUGCG-3'; antisense: 5'-CAUUA UUACUCACGGUACGAUU-3'; GenePharma), $100 \mathrm{ng}$ HOTAIR-plasmid + $100 \mathrm{nM}$ mimic control or $100 \mathrm{ng}$
HOTAIR-plasmid + $100 \mathrm{nM}$ miR-126 mimic using Polyplus transfection reagent (Invitrogen; Thermo Fisher Scientific, Inc.). At $24 \mathrm{~h}$ post-transfection, the cells were used for subsequent experiments.

Psoriasis model establishment. HaCaT cells $\left(5 \times 10^{4}\right.$ cells per well) were seeded into a 6-well plate. After reaching $80-90 \%$ confluence, the medium was replaced with serum-free DMEM at $37^{\circ} \mathrm{C}$ for $24 \mathrm{~h}$. HaCaT cells were then treated with $100 \mathrm{ng} / \mathrm{ml} \mathrm{IL-22}$ and serum-starved at $37^{\circ} \mathrm{C}$ for an additional 24 h (38).

Reverse transcription-quantitative PCR (RT-qPCR) analysis. TotalRNA was extracted using TRIzol ${ }^{\mathrm{TM}}$ reagent (Thermo Fisher Scientific, Inc.) according to the manufacturer's protocol. RNA extraction was considered successful when three bands were observed in the nucleic acid gel. When RNA extraction was successful, total RNA was reverse-transcribed into cDNA using a reverse transcription kit (Vazyme Biotech Co., Ltd.) according to the manufacturer's instructions. Subsequently, qPCR was performed using SYBR Green PCR kit (Vazyme Biotech Co., Ltd.). The thermocycling conditions were as follows: Initial denaturation for $5 \mathrm{~min}$ at $95^{\circ} \mathrm{C}$; followed by 38 cycles of denaturation at $94^{\circ} \mathrm{C}$ for $1 \mathrm{~min}$, annealing at $60^{\circ} \mathrm{C}$ for $1 \mathrm{~min}$ and extension at $72^{\circ} \mathrm{C}$ for $1 \mathrm{~min}$, followed by a final extension step at $72^{\circ} \mathrm{C}$ for $10 \mathrm{~min}$. mRNA and miRNA expression levels were quantified using the $2^{-\Delta \Delta \mathrm{Cq}}$ method (39) and normalized to the internal reference genes GAPDH and U6, respectively. All samples were assessed in triplicate and all experiments were repeated three times. The primer sequences used were as follows: GAPDH, forward 5'-ATTCCATGGCA CCGTCAAGGCTGA-3' and reverse 5'-TTCTCCATGGTG GTGAAGACGCCA-3'; U6, forward 5'-GCTTCGGCA GCACATATACTAAAAT-3' and reverse 5'-CGCTTCACGAA TTTGCGTGTCAT-3'; HOTAIR, forward 5'-CAGTGGGGA ACTCTGACTCG-3' and reverse 5'-GTGCCTGGTGCTGTC TTACC-3'; and miR-126 forward 5'-GCTGTCAGT TTGTCAA ATA-3' and reverse 5'-GTGCAGGGTCCGAGGT-3'.

Western blotting. Total protein was extracted from cells using RIPA buffer (Beyotime Institute of Biotechnology) and quantified using a bicinchoninic acid assay kit (Pierce; Thermo Fisher Scientific, Inc.). Equal amounts of proteins (40 $\mu \mathrm{g}$ per lane) were separated via $12 \%$ SDS-PAGE for $40 \mathrm{~min}$ and transferred to PVDF membranes (EMD Millipore). The membranes were blocked for $1.5 \mathrm{~h}$ at room temperature with $5 \%$ non-fat milk. Subsequently, the membranes were incubated at $4^{\circ} \mathrm{C}$ overnight with the following primary antibodies: Anti-cleaved caspase-3 (cat no. ab32042; 1:1,000; Abcam), anti-pro-caspase-3 (cat no. ab32499; 1:1,000; Abcam) and GAPDH (cat no. ab9485; 1:1,000; Abcam). Following primary incubation, the membranes were incubated with an anti-rabbit horseradish peroxidase conjugated IgG secondary antibody (cat no. 7074; 1:2,000; Cell Signaling Technology, Inc.) for $2 \mathrm{~h}$. Protein bands were visualized using the enhanced chemiluminescence method (Cytiva). GAPDH was used as the loading control.

Flow cytometry. Cell apoptosis was assessed using the Annexin V/propidium iodide (PI) Apoptosis Detection 
kit (Beyotime Institute of Biotechnology). Briefly, cells $\left(5 \times 10^{4}\right.$ cells per well) were plated in 6 -well plates overnight. On the following day, $\mathrm{HaCaT}$ cells were transfected with plasmid or mimic. Subsequently, cells were directly collected, centrifuged at $1,000 \mathrm{xg}$ at $4^{\circ} \mathrm{C}$ for $5 \mathrm{~min}$, and resuspended in $100 \mu \mathrm{l}$ FITC-binding buffer. Subsequently, cells were incubated with $5 \mu 1$ ready-to-use Annexin V-FITC (BD Biosciences) and $5 \mu 1$ $\mathrm{PI}$ in the dark at $4^{\circ} \mathrm{C}$ for $30 \mathrm{~min}$. Cell apoptosis was assessed using a BD FACSCalibur flow cytometer (BD Biosciences). Data were analyzed using CellQuest ${ }^{\mathrm{TM}}$ software, version 5.1 (BD Biosciences).

Dual-luciferase reporter assay. The wild-type (WT) or mutant (MUT) 3' untranslated region (UTR) of HOTAIR was cloned into the pmiRGLO vector(Promega Corporation). Recombinant plasmids were acquired using the EndoFree Plasmid Maxi kit (Vazyme Biotech Co., Ltd.). HaCaT cells $\left(5 \times 10^{4}\right.$ cells per well) were co-transfected with $100 \mathrm{nM}$ miR-126 mimic or $100 \mathrm{nM}$ mimic control and $1 \mathrm{ng}$ MUT-3'UTR-HOTAIR or $1 \mathrm{ng}$ WT-3'UTR-HOTAIR at $37^{\circ} \mathrm{C}$ for $48 \mathrm{~h}$. Renilla luciferase pRL-TK vector (Promega Corporation) was used as the control. At $48 \mathrm{~h}$ post-transfection, luciferase activity was measured using a dual-luciferase reporter assay system (Promega Corporation). Firefly luciferase activity was normalized to Renilla luciferase activity.

MTT assay. Cell viability was assessed by performing an MTT assay. Transfected $\mathrm{HaCaT}$ cells were treated with $100 \mathrm{ng} / \mathrm{ml}$ IL-22 at $37^{\circ} \mathrm{C}$ for $24 \mathrm{~h}$. HaCaT cells were plated into a 96-well plate and incubated at $37^{\circ} \mathrm{C}$ for 24,48 or $72 \mathrm{~h}$. Subsequently, $20 \mu \mathrm{l}$ MTT (5 mg/ml; Sigma-Aldrich; Merck KGaA) was added into each well at $37^{\circ} \mathrm{C}$ for $4 \mathrm{~h}$. Absorbance was measured using a multifunctional plate reader (BD Biosciences) at a wavelength of $570 \mathrm{~nm}$. Data are presented as the mean \pm standard deviations of three separate experiments.

Caspase-3 activity detection. Caspase-3 activity was detected using a caspase-3 activity detection kit (Beyotime Institute of Biotechnology). Following transfection, HaCaT cells were treated with $100 \mathrm{ng} / \mathrm{ml} \mathrm{IL}-22$ at $37^{\circ} \mathrm{C}$ for $24 \mathrm{~h}$. Subsequently, cells were collected by centrifugation $(600 \mathrm{x}$ g for $5 \mathrm{~min}$ at $4^{\circ} \mathrm{C}$ ) and caspase- 3 enzyme activity in cells was measured at a wavelength of $405 \mathrm{~nm}$ using a multifunctional plate reader (BD Biosciences).

Statistical analysis. Statistical analyses were performed using GraphPad Prism software (version 6; GraphPad Software, Inc.). Comparisons between two groups were analyzed using the unpaired Student's t-test. Comparisons among multiple groups were analyzed using one-way ANOVA followed by Tukey's post hoc test. Data are presented as the mean \pm SD from at least three independent experiments. $\mathrm{P}<0.05$ was considered to indicate a statistically significant difference.

\section{Results}

HOTAIR is downregulated in IL-22-stimulated HaCaT cells. To explore HOTAIR expression in psoriasis, an in vitro cell model of psoriasis was established. Cells were starved in serum-free DMEM for $24 \mathrm{~h}$ and then stimulated with $100 \mathrm{ng} / \mathrm{ml}$

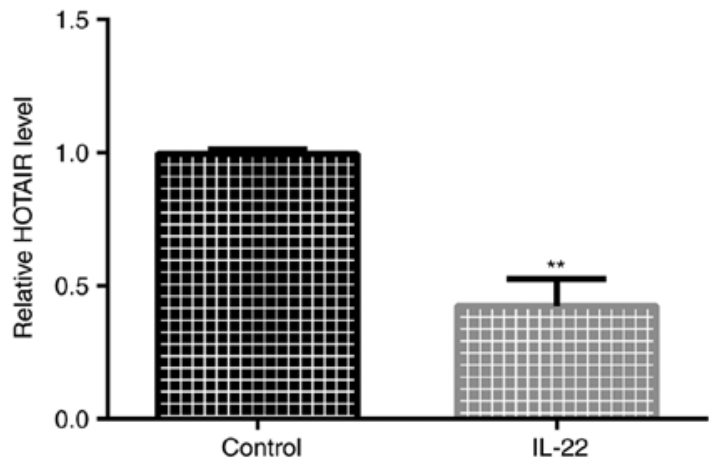

Figure 1. HOTAIR expression in IL-22-stimulated HaCaT cells. Reverse transcription-quantitative PCR analysis was performed to detect the relative expression of HOTAIR in IL-22-treated HaCaT cells. Data are presented as the mean $\pm \mathrm{SD} .{ }^{* *} \mathrm{P}<0.01$ vs. control group. HOTAIR, HOX transcript antisense RNA; IL, interleukin.

IL-22 in serum-free DMEM for $24 \mathrm{~h}$. The RT-qPCR results indicated that HOTAIR was downregulated in IL-22-treated HaCaT cells (Fig. 1).

HOTAIR binds to miR-126. Previous studies $(36,37)$ reported the existence of a mutual binding site between HOTAIR and miR-126 (Fig. 2A). A luciferase assay was performed to investigate the interaction between HOTAIR and miR-126. $\mathrm{HaCaT}$ cells were co-transfected with a luciferase plasmid containing the IncRNA HOTAIR sequence (HOTAIR-WT and HOTAIR-MUT) and miRNA-126 mimic. The results indicated that miR-126 suppressed the luciferase activity of HOTAIR-WT but did not alter the luciferase activity of HOTAIR-MUT (Fig. 2B). RT-qPCR analysis was performed to detect miR-126 expression in $\mathrm{HaCaT}$ cells that were treated with IL-22 and untreated cells. The results indicated that miR-126 was upregulated in IL-22-stimulated HaCaT cells (Fig. 2C).

Transfection efficiency of HOTAIR and miR-126 in HaCaT cells. HaCaT cells were transfected with control-plasmid or HOTAIR-plasmid. The RT-qPCR results indicated that, compared with the control-plasmid group, HOTAIR-plasmid increased HOTAIR expression in HaCaT cells (Fig. 3A). $\mathrm{HaCaT}$ cells were transfected with mimic control or miR-126 mimic. The RT-qPCR results indicated that, compared with the mimic control group, miR-126 mimic increased miR-126 expression in $\mathrm{HaCaT}$ cells (Fig. 3B). HaCaT cells were also transfected with HOTAIR-plasmid + mimic control or HOTAIR-plasmid + miR-126 mimic for $24 \mathrm{~h}$. The results suggested that HOTAIR-plasmid significantly reduced miR-126 expression in $\mathrm{HaCaT}$ cells, which was reversed by miR-126 mimic (Fig. 3C).

HOTAIR suppresses cell proliferation and induces apoptosis in IL-22-stimulated HaCaT cells by regulating miR-126 expression. Subsequently, MTT assays and flow cytometry were performed to detect cell proliferation and apoptosis, respectively. The MTT assay suggested that, compared with the control group, $\mathrm{HaCaT}$ cell proliferation was increased in the IL-22 group. In addition, compared with the IL-22 + control-plasmid group, HOTAIR-plasmid suppressed 

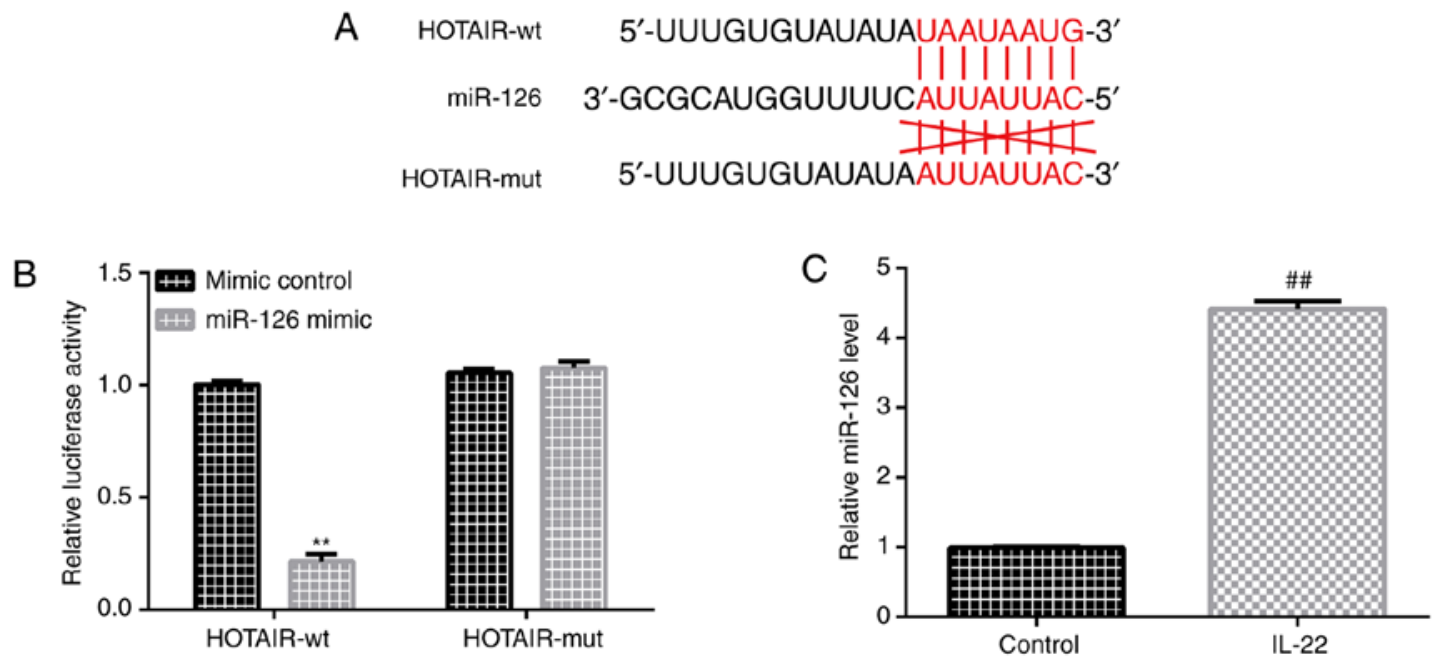

Figure 2. Binding sites between HOTAIR and miR-126. (A) Potential binding sites between HOTAIR and miR-126. (B) The dual-luciferase reporter gene assay was performed to confirm the binding sites between HOTAIR and miR-126. (C) Reverse transcription-quantitative PCR analysis was performed to detect miR-126 expression in IL-22-treated HaCaT cells. Data are presented as the mean $\pm \mathrm{SD}$. ${ }^{* *} \mathrm{P}<0.01$ vs. mimic control group; ${ }^{\# \#} \mathrm{P}<0.01$ vs. control group. HOTAIR, HOX transcript antisense RNA; miR, microRNA; wt, wild-type; mut, mutant; IL, interleukin.
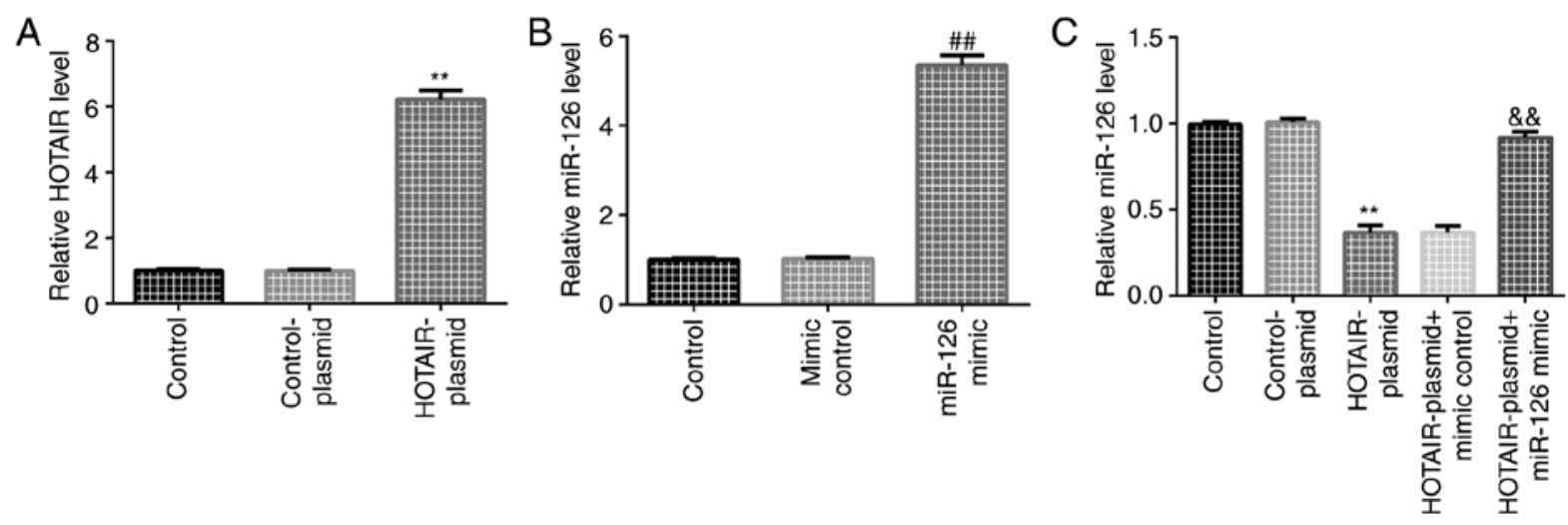

Figure 3. Transfection efficiency of HOTAIR and miR-126 in HaCaT cells. (A) RT-qPCR analysis was performed to detect HOTAIR expression in the control-plasmid and HOTAIR-plasmid groups. (B) RT-qPCR analysis was performed to detect miR-126 expression in the mimic control and miR-126 mimic groups. (C) RT-qPCR analysis was performed to detect miR-126 expression in the HOTAIR-plasmid + mimic control and HOTAIR-plasmid + miR-126 mimic groups. Data are presented as the mean $\pm \mathrm{SD}$. ${ }^{* *} \mathrm{P}<0.01$ vs. control-plasmid group; ${ }^{\# \#} \mathrm{P}<0.01$ vs. mimic control group; ${ }^{\text {\&\&}} \mathrm{P}<0.01 \mathrm{vs}$. HOTAIR-plasmid + mimic control group. HOTAIR, HOX transcript antisense RNA; miR, microRNA; RT-qPCR, reverse transcription-quantitative PCR; IL, interleukin.

cell proliferation, which was reversed by miR-126 mimic (Fig. 4A). The flow cytometry results indicated that, compared with the control group, cell apoptosis was decreased in IL-22-induced HaCaT cells (Fig. 4B and C). Furthermore, the caspase-3 activity assay results indicated that compared with the control group, caspase-3 activity was significantly decreased in the IL-22 group (Fig. 4D). The western blotting results indicated that compared with the control group, cleaved caspase-3 protein expression and the cleaved caspase-3/caspase-3 ratio was decreased in IL-22-induced $\mathrm{HaCaT}$ cells (Fig. 4E and F). Compared with the IL-22 + control-plasmid group, HOTAIR-plasmid increased cell apoptosis (Fig. 4B and C), promoted caspase-3 activity (Fig. 4D), increased cleaved caspase- 3 protein expression and enhanced the cleaved caspase-3/caspase-3 ratio (Fig. 4E and F), whereas miR-126 mimic reversed these effects.

HOTAIR-plasmid reduces miR-126 expression. Finally, RT-qPCR analysis was performed to detect miR-126 expression. Compared with the control group, miR-126 expression was significantly increased in the IL-22 group. Compared with the IL-22 + control-plasmid group, HOTAIR-plasmid reduced miR-126 expression, which was reversed by miR-126 mimic (Fig. 5).

\section{Discussion}

IncRNAs have been found to be closely associated with the occurrence and development of psoriasis $(24,25)$. The focus of the present study was the IncRNA HOTAIR, which has been extensively investigated (40). Accumulating evidence suggests that abnormal expression of HOTAIR is implicated in cancer development, including lung and gastric cancer, as well as hepatocellular carcinoma (41-43). Zhang et al (41) reported that HOTAIR promoted cell viability, migration and invasion. Gao et al (43) demonstrated that reduced HOTAIR expression decreased hepatocellular carcinoma growth. Liu et al (42) indicated that HOTAIR overexpression increased 

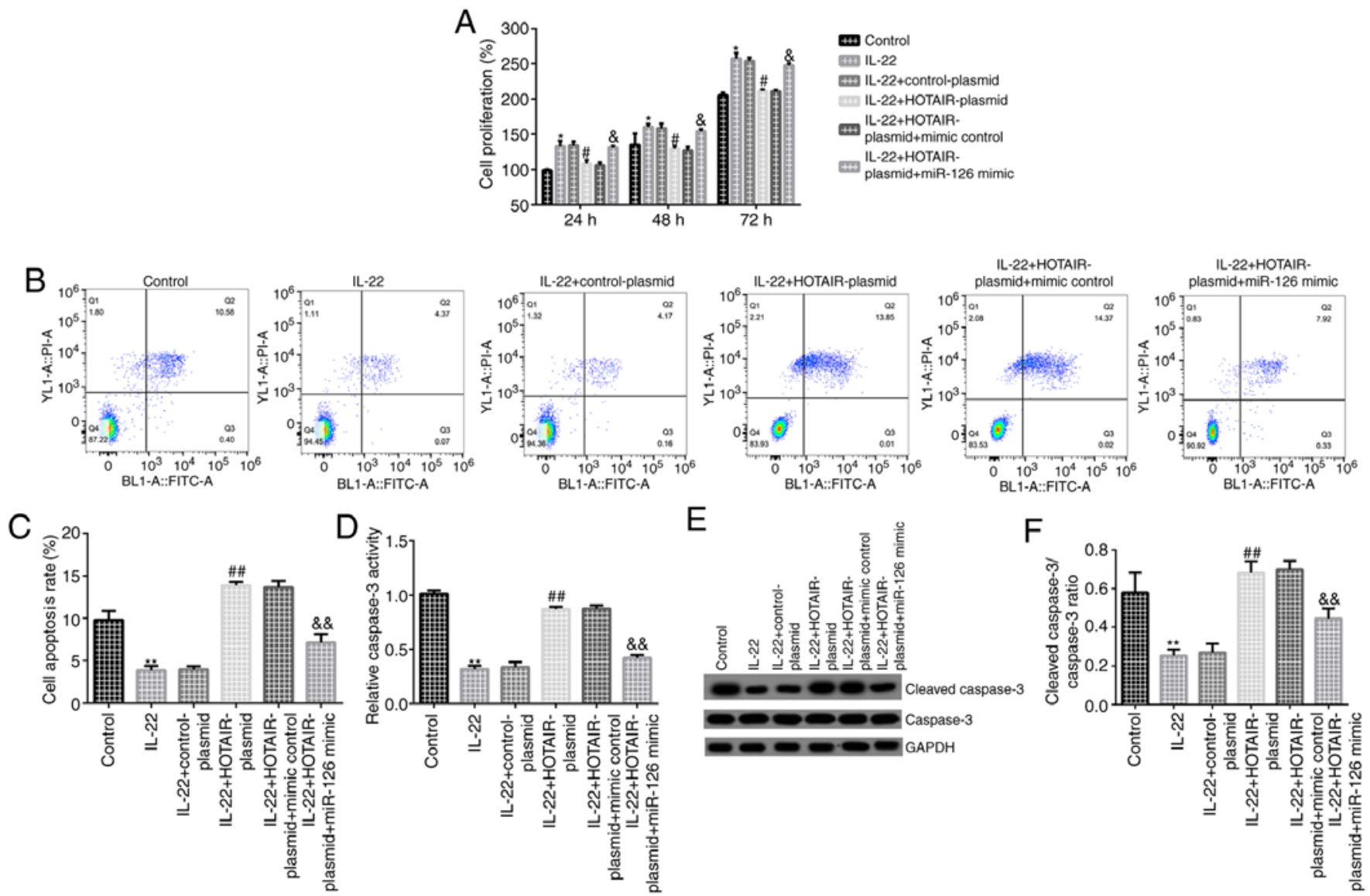

Figure 4. Effects of HOTAIR on IL-22-stimulated HaCaT cell proliferation and apoptosis. HaCaT cells were transfected with control-plasmid, HOTAIR-plasmid, HOTAIR-plasmid + mimic control or HOTAIR-plasmid + miR-126 mimic for $24 \mathrm{~h}$. After $24 \mathrm{~h}$, cells were stimulated with $100 \mathrm{ng} / \mathrm{ml} \mathrm{IL-22} \mathrm{for} \mathrm{a} \mathrm{further} 24 \mathrm{~h}$ (A) The MTT assay was conducted to detect cell proliferation at 24,48 and $72 \mathrm{~h}$. (B) Flow cytometry was performed to detect cell apoptosis. (C) Cell apoptosis rate. (D) Caspase-3 activity. (E) Western blotting was performed to measure cleaved caspase-3 and caspase-3 protein expression levels in different groups (F) Cleaved caspase-3/caspase-3 ratio. Data are presented as the mean $\pm \mathrm{SD} .{ }^{*} \mathrm{P}<0.05,{ }^{* *} \mathrm{P}<0.01$ vs. control group; ${ }^{*} \mathrm{P}<0.05$, ${ }^{\# /} \mathrm{P}<0.01$ vs. IL-22 + control-plasmid group; ${ }^{\circledR} \mathrm{P}<0.05$, \&\& $\mathrm{P}<0.01$ vs. IL-22 + HOTAIR-plasmid + mimic control group.HOTAIR, HOX transcript antisense RNA; miR, microRNA; IL, interleukin.

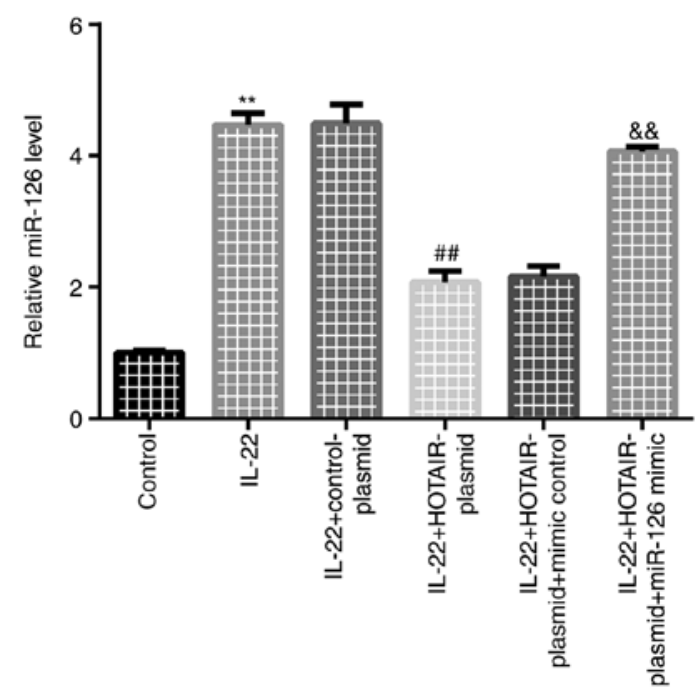

Figure 5. HOTAIR-plasmid reduces miR-126 expression in IL-22-induced HaCaTcells.HaCaTcellsweretransfected withcontrol-plasmid,HOTAIR-plasmid, HOTAIR-plasmid + mimic control or HOTAIR-plasmid + miR-126 mimic for $24 \mathrm{~h}$. After $24 \mathrm{~h}$, cells were stimulated with $100 \mathrm{ng} / \mathrm{ml} \mathrm{IL-22}$ for a further $24 \mathrm{~h}$. Reverse transcription-quantitative PCR analysis was performed to measure miR-126 expression. Data are presented as the mean $\pm \mathrm{SD} .{ }^{* *} \mathrm{P}<0.01$ vs. control group; ${ }^{\# \#} \mathrm{P}<0.01$ vs. IL- $22+$ control-plasmid group; ${ }^{\& \&} \mathrm{P}<0.01$ vs. IL-22 + HOTAIR-plasmid + mimic control group. HOTAIR, HOX transcript antisense RNA; miR, microRNA; IL, interleukin. cell viability via miR-331-3p in gastric cancer. Furthermore, a previous study indicated that HOTAIR participated in psoriasis development (32). However, the expression and role of HOTAIR in psoriasis is not completely understood. Psoriasis is a T-cell-mediated chronic skin condition manifesting clinically as erythema and scaly skin. The primary pathological process of psoriasis is excessive keratinocyte proliferation and continuous skin inflammation $(44,45)$, but the pathogenesis of the condition has yet to be fully elucidated. Therefore, the aim of the present study was to investigate the underlying mechanism in order to identify novel therapeutic targets for psoriasis.

First, the expression of HOTAIR was determined in an in vitro cell model of psoriasis, which was established by stimulating $\mathrm{HaCaT}$ cells with $100 \mathrm{ng} / \mathrm{ml} \mathrm{IL-22}$ for $24 \mathrm{~h}$ in serum-free DMEM. The findings indicated that HOTAIR was downregulated in IL-22-stimulated HaCaT cells. In addition, Yan et al (36) demonstrated that HOTAIR had a binding site with miR-126 in gastric cancer (36). Therefore, a dual-luciferase reporter assay was performed in the present study to investigate the interaction between HOTAIR and miR-126. The results also indicated that there was a mutual binding site between HOTAIR and miR-126.

miRNAs have been demonstrated to play key roles in psoriasis (33-35). Furthermore, miRNAs participate in the 
development of immune cells, maintain immune homeostasis and regulate certain immune regulatory factors (46). miR-126 has been found to participate in the occurrence and development of multiple immune diseases, such as rheumatoid arthritis, systemic lupus erythematosus (SLE), inflammatory bowel disease and psoriasis (47-50). Qu et al (47) reported that miR-126 promoted cell proliferation via the PI3K/AKT signaling pathway. miR-126 was upregulated in the CD4 ${ }^{+}$ $T$ cells of patients with SLE and enhanced T-cell autoreactivity to promote SLE progression. Feng et al (50) demonstrated that miR-126 was upregulated in patients with psoriasis. Consistent with previous results, the present study demonstrated that miR-126 was upregulated in IL-22-stimulated $\mathrm{HaCaT}$ cells, and that miR-126 expression was negatively correlated with HOTAIR expression. Subsequently, the effects of HOTAIR on IL-22-stimulated HaCaT cell proliferation and apoptosis were investigated. The results indicated that HOTAIR-plasmid suppressed cell viability and increased cell apoptosis, and these effects were reversed by miR-126 mimic. Therefore, the findings of the present study suggested that HOTAIR/miR-126 may represent promising novel targets for the treatment of psoriasis.

In conclusion, HOTAIR inhibited IL-22-induced $\mathrm{HaCaT}$ cell proliferation and increased apoptosis by regulating miR-126 expression, indicating that HOTAIR may play a protective role in psoriasis. However, this was an in vitro basic study of HOTAIR in psoriasis, and there were certain limitations: Experiments in vivo were not conducted; the target genes of miR-126 were not analyzed in depth; in addition, the correlation between the expression of HOTAIR/miR-126 and clinicopathological parameters in patients with psoriasis was not analyzed. Despite these limitations, however, the present study provides new potential targets for the clinical treatment of psoriasis and a theoretical basis for the development of psoriasis treatment strategies. In view of the aforementioned limitations, the role of HOTAIR/miR-126 in psoriasis will be further investigated in future studies.

\section{Acknowledgements}

Not applicable.

\section{Funding}

No funding was received.

\section{Availability of data and materials}

The datasets used and/or analyzed during the current study are available from the corresponding author on reasonable request.

\section{Authors' contributions}

WZ contributed to study design, data collection, statistical analysis, data interpretation and manuscript preparation. BG, SC, JL and YS contributed to data collection and statistical analysis. All authors have read and approved the final version of the manuscript.

\section{Ethics approval and consent to participate}

Not applicable.

\section{Patient consent for publication}

Not applicable.

\section{Competing interests}

The authors declare that they have no competing interests.

\section{References}

1. Liu Q, Wu DH, Han L, Deng JW, Zhou L, He R, Lu CJ and Mi QS: Roles of microRNAs in psoriasis: Immunological functions and potential biomarkers. Exp Dermatol 26: 359-367, 2017.

2. Boehncke WH and Schön MP: Psoriasis. Lancet 386: 983-994, 2015.

3. Parisi R, Symmons DP, Griffiths CE and Ashcroft DM; Identification and Management of Psoriasis and Associated ComorbidiTy (IMPACT) project team: Global epidemiology of psoriasis: A systematic review of incidence and prevalence. J Invest Dermatol 133: 377-385, 2013.

4. Ritchlin CT, Colbert RA and Gladman DD: Psoriatic arthritis. N Engl J Med 376: 957-970, 2017.

5. Liakou AI and Zouboulis CC: Links and risks associated with psoriasis and metabolic syndrome. Psoriasis (Auckl) 5: 125-128, 2015.

6. Vide J and Magina S: Moderate to severe psoriasis treatment challenges through the era of biological drugs. An Bras Dermatol 92: 668-674, 2017.

7. Roubille C, Richer V, Starnino T, McCourt C, McFarlane A, Fleming P, Siu S, Kraft J, Lynde C, Pope J, et al: The effects of tumour necrosis factor inhibitors, methotrexate, non-steroidal anti-inflammatory drugs and corticosteroids on cardiovascular events in rheumatoid arthritis, psoriasis and psoriatic arthritis: A systematic review and meta-analysis. Ann Rheum Dis 74: 480-489, 2015.

8. Geller S, Xu H, Lebwohl M, Nardone B, Lacouture ME and Kheterpal M: Malignancy risk and recurrence with psoriasis and its treatments: A concise update. Am J Clin Dermatol 19: 363-375, 2018.

9. Boniface K, Bernard FX, Garcia M, Gurney AL, Lecron JC and Morel F: IL-22 inhibits epidermal differentiation and induces proinflammatory gene expression and migration of human keratinocytes. J Immunol 174: 3695-3702, 2005.

10. Wolk K, Witte E, Wallace E, Döcke WD, Kunz S, Asadullah K, Volk HD, Sterry W and Sabat R: IL-22 regulates the expression of genes responsible for antimicrobial defense, cellular differentiation, and mobility in keratinocytes: A potential role in psoriasis. Eur J Immunol 36: 1309-1323, 2006.

11. Amaral PP, Dinger ME, Mercer TR and Mattick JS: The eukaryotic genome as an RNA machine. Science 319: 1787-1789, 2008.

12. Guttman M, Amit I, Garber M, French C, Lin MF, Feldser D, Huarte M, Zuk O, Carey BW, Cassady JP, et al: Chromatin signature reveals over a thousand highly conserved large non-coding RNAs in mammals. Nature 458: 223-227, 2009.

13. Nagano $T$ and Fraser P: No-nonsense functions for long noncoding RNAs. Cell 145: 178-181, 2011.

14. Lekka $E$ and Hall J: Noncoding RNAs in disease. FEBS Lett 592: 2884-2900, 2018.

15. Kopp F and Mendell JT: Functional classification and experimental dissection of long noncoding RNAs. Cell 172: 393-407, 2018.

16. Wang KC and Chang HY: Molecular mechanisms of long noncoding RNAs. Mol Cell 43: 904-914, 2011.

17. Liu Y, Ferguson JF, Xue C, Ballantyne RL, Silverman IM, Gosai SJ, Serfecz J, Morley MP, Gregory BD, Li M, et al: Tissue-specific RNA-Seq in human evoked inflammation identifies blood and adipose LincRNA signatures of cardiometabolic diseases. Arterioscler Thromb Vasc Biol 34: 902-912, 2014. 
18. Liu YW, Sun M, Xia R, Zhang EB, Liu XH, Zhang ZH, $\mathrm{Xu}$ TP, De W, Liu BR and Wang ZX: LincHOTAIR epigenetically silences miR34a by binding to PRC2 to promote the epithelial-to-mesenchymal transition in human gastric cancer Cell Death Dis 6: e1802, 2015.

19. Chang S, Chen B, Wang X, Wu K and Sun Y: Long non-coding RNA XIST regulates PTEN expression by sponging miR-181a and promotes hepatocellular carcinoma progression. BMC Cancer 17: 248, 2017.

20. Lu W, Zhang H, Niu Y, Wu Y, Sun W, Li H, Kong J, Ding K, Shen HM, Wu $\mathrm{H}$, et al: Long non-coding RNA linc00673 regulated non-small cell lung cancer proliferation, migration, invasion and epithelial mesenchymal transition by sponging miR-150-5p. Mol Cancer 16: 118, 2017.

21. Zheng J, Huang X, Tan W, Yu D, Du Z, Chang J, Wei L, Han Y, Wang C, Che X, et al: Pancreatic cancer risk variant in LINC00673 creates a miR-1231 binding site and interferes with PTPN11 degradation. Nat Genet 48: 747-757, 2016.

22. Sha M, Lin M, Wang J, Ye J, Xu J, Xu N and Huang J: Long non-coding RNA MIAT promotes gastric cancer growth and metastasis through regulation of miR-141/DDX5 pathway. J Exp Clin Cancer Res 37: 58, 2018.

23. Lu Z, Li Y, Wang J, Che Y, Sun S, Huang J, Chen Z and He J: Long non-coding RNA NKILA inhibits migration and invasion of non-small cell lung cancer via NF- $\mathrm{kB} /$ Snail pathway. J Exp Clin Cancer Res 36: 54, 2017.

24. Yan J, Song J, Qiao M, Zhao X, Li R, Jiao J and Sun Q: Long noncoding RNA expression profile and functional analysis in psoriasis. Mol Med Rep 19: 3421-3430, 2019.

25. Ahn R, Gupta R, Lai K, Chopra N, Arron ST and Liao W: Network analysis of psoriasis reveals biological pathways and roles for coding and long non-coding RNAs. BMC Genomics 17: $841,2016$.

26. Jia HY, Zhang K, Lu WJ, Xu GW, Zhang JF and Tang ZL: lncRNA MEG3 influences the proliferation and apoptosis of psoriasis epidermal cells by targeting miR-21/caspase-8. BMC Mol Cell Biol 20: 46, 2019 .

27. Gao J, Chen F, Hua M, Guo J, Nong Y, Tang Q, Zhong F and Qin L: Knockdown of lncRNA MIR31HG inhibits cell proliferation in human HaCaT keratinocytes. Biol Res 51: 30, 2018.

28. Qiao M, Li R, Zhao X, Yan J and Sun Q: Up-regulated lncRNA-MSX2P1 promotes the growth of IL-22-stimulated keratinocytes by inhibiting miR-6731-5p and activating S100A7. Exp Cell Res 363: 243-254, 2018.

29. Széll M, Danis J, Bata-Csörgó Z and Kemény L: PRINS, a primate-specific long non-coding RNA, plays a role in the keratinocyte stress response and psoriasis pathogenesis. Pflugers Arch 468: 935-943, 2016.

30. Tang Q and Hann SS: HOTAIR: An oncogenic long non-coding RNA in human cancer. Cell Physiol Biochem 47: 893-913, 2018.

31. Yang T, He X, Chen A, Tan K and Du X: lncRNA HOTAIR contributes to the malignancy of hepatocellular carcinoma by enhancing epithelial-mesenchymal transition via sponging miR-23b-3p from ZEB1. Gene 670: 114-122, 2018.

32. Rakhshan A, Zarrinpour N, Moradi A, Ahadi M, Omrani MD, Ghafouri-Fard S and Taheri M: A single nucleotide polymorphism within HOX Transcript Antisense RNA (HOTAIR) is associated with risk of psoriasis. Int J Immunogenet 47: 430-434, 2020

33. Xu N, Brodin P, Wei T, Meisgen F, Eidsmo L, Nagy N, Kemeny L, Ståhle M, Sonkoly E and Pivarcsi A: miR-125b, a microRNA downregulated in psoriasis, modulates keratinocyte proliferation by targeting FGFR2. J Invest Dermatol 131: 1521-1529, 2011.

34. Xu L, Leng H, Shi X, Ji J, Fu J and Leng H: miR-155 promotes cell proliferation and inhibits apoptosis by PTEN signaling pathway in the psoriasis. Biomed Pharmacother 90: 524-530, 2017.
35. Cheung L, Fisher RM, Kuzmina N, Li D, Li X, Werngren O, Blomqvist L, Ståhle M and Landén NX: Psoriasis skin inflammation-induced microRNA-26b targets NCEH1 in underlying subcutaneous adipose tissue. J Invest Dermatol 136: 640-648, 2016.

36. Yan J, Dang Y, Liu S, Zhang Y and Zhang G: lncRNA HOTAIR promotes cisplatin resistance in gastric cancer by targeting miR-126 to activate the PI3K/AKT/MRP1 genes. Tumour Biol 37: 30, 2016.

37. Jiang B, Tang Y, Wang H, Chen C, Yu W, Sun H, Duan M, Lin $X$ and Liang P: Down-regulation of long non-coding RNA HOTAIR promotes angiogenesis via regulating miR-126/SCEL pathways in burn wound healing. Cell Death Dis 11: 61, 2020.

38. Wang R, Wang FF, Cao HW and Yang JY: miR-223 regulates proliferation and apoptosis of IL-22-stimulated HaCat human keratinocyte cell lines via the PTEN/Akt pathway. Life Sci 230: 28-34, 2019.

39. Livak KJ and Schmittgen TD: Analysis of relative gene expression data using real-time quantitative PCR and the 2(- $\Delta \Delta \mathrm{C}(\mathrm{T}))$ Method. Methods 25: 402-408, 2001.

40. Rinn JL, Kertesz M, Wang JK, Squazzo SL, Xu X, Brugmann SA Goodnough LH, Helms JA, Farnham PJ, Segal E, et al: Functional demarcation of active and silent chromatin domains in human HOX loci by noncoding RNAs. Cell 129: 1311-1323, 2007.

41. Zhang C, Xu L, Deng G, Ding Y, Bi K, Jin H, Shu J, Yang J, Deng $\mathrm{H}$, Wang Z, et al: Exosomal HOTAIR promotes proliferation, migration and invasion of lung cancer by sponging miR-203. Sci China Life Sci 63: 1265-1268, 2020.

42. Liu XH, Sun M, Nie FQ, Ge YB, Zhang EB, Yin DD, Kong R, Xia R, Lu KH, Li JH, et al: lnc RNA HOTAIR functions as a competing endogenous RNA to regulate HER 2 expression by sponging miR-331-3p in gastric cancer. Mol Cancer 13: 92, 2014.

43. Gao JZ, Li J, Du JL and Li XL: Long non-coding RNA HOTAIR is a marker for hepatocellular carcinoma progression and tumor recurrence. Oncol Lett 11: 1791-1798, 2016.

44. Lowes MA, Suárez-Fariñas M and Krueger JG: Immunology of psoriasis. Annu Rev Immunol 32: 227-255, 2014.

45. Jadali $\mathrm{Z}$ and Eslami MB: T cell immune responses in psoriasis. Iran J Allergy Asthma Immunol 13: 220-230, 2014.

46. Soltanzadeh-Yamchi M, Shahbazi M, Aslani S and Mohammadnia-Afrouzi M: MicroRNA signature of regulatory T cells in health and autoimmunity. Biomed Pharmacother 100: 316-323, 2018.

47. Qu Y, Wu J, Deng JX, Zhang YP, Liang WY, Jiang ZL, Yu QH and Li J: MicroRNA-126 affects rheumatoid arthritis synovial fibroblast proliferation and apoptosis by targeting PIK3R2 and regulating PI3K-AKT signal pathway. Oncotarget 7: 74217-74226, 2016.

48. Liang Y, Zhao S, Liang G, Zhao M and Lu Q: DNA methylation status of miR-126 and its host gene EGFL7 in CD4 $4^{+} \mathrm{T}$ cells from patients with systemic lupus erythematosus. Zhong Nan Da Xue Xue Bao Yi Xue Ban 38: 793-797, 2013 (In Chinese).

49. Thorlacius-Ussing G, Schnack Nielsen B, Andersen V, Holmstrøm K and Pedersen AE: Expression and localization of miR-21 and miR-126 in mucosal tissue from patients with inflammatory bowel disease. Inflamm Bowel Dis 23: 739-752, 2017.

50. Feng SK, Wang L, Liu W, Zhong Y and Xu SJ: miR-126 correlates with increased disease severity and promotes keratinocytes proliferation and inflammation while suppresses cells' apoptosis in psoriasis. J Clin Lab Anal 32: e22588, 2018.

This work is licensed under a Creative Commons Attribution-NonCommercial-NoDerivatives 4.0 International (CC BY-NC-ND 4.0) License. 